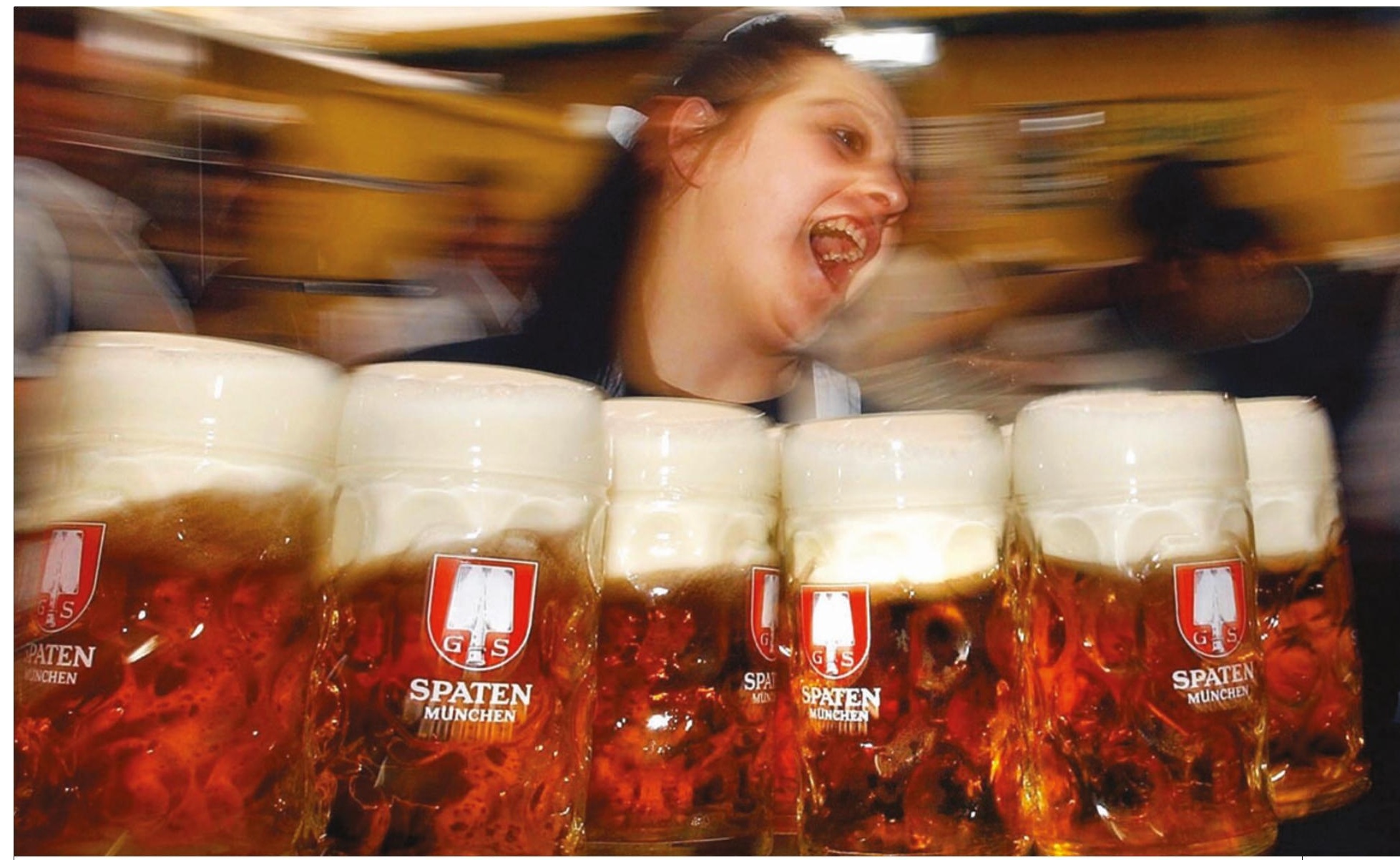

\title{
The demon drink
}

\section{A little alcohol can be good for you. But, collectively, our drinking habits are seriously damaging our health. Can public-health officials promote the message of moderation? Helen Pearson investigates.}

A lcohol and tobacco are the terrible twins of public health. Both increase the risk of cancer and other lifethreatening diseases. Both are promoted aggressively by a powerful industry. And both can be horribly addictive.

Yet while packets of cigarettes bear stark health warnings and smokers have to skulk outside their workplaces to indulge the habit, alcohol has largely escaped such vilification. Indeed, as public-health officials concentrate on our expanding waistlines, you could be forgiven for thinking that drinking doesn't pose serious health problems. "It's even getting a softer ride than food these days," says Robin Room, director of the Centre for Social Research on Drugs at Stockholm University in Sweden.

But the latest figures on the global burden of disease suggest that it's time to rethink. According to a new report from the World Health Organization (WHO), the harm caused by alcohol nearly equals that from smoking ${ }^{1}$. Add in the social consequences of drinking, including wrecked families and lost days at work, which were excluded from the WHO report, and alcohol should arguably be the greater concern.

There are some small signs that alcohol is surfacing on the global health agenda. For the first time in 20 years, national delegations at May's World Health Assembly, the annual meeting in Geneva, Switzerland, that sets the WHO's agenda, will consider a resolution that proposes making alcohol a priority for action. "It is a sign of something good," says Jürgen Rehm, who studies public-health policy at the University of Toronto in Canada.

\section{Mixed messages}

One reason that alcohol has not been targeted so effectively by public-health campaigns is that its detrimental effects are less clear-cut than those of smoking. Tobacco is $100 \%$ bad: even one cigarette does you harm. But with alcohol, the picture is much more complicated. Although a handful of researchers still question the idea that moderate drinking is beneficial, the consensus from epidemiological studies is that alcohol can improve health if taken in small doses - primarily by reducing the risk of heart attacks in older people (see 'A little of what you fancy', overleaf).

On the surface, this health message seems simple, but its consequences are not. Most of us like a drink, many valuing alcohol as a social lubricant and reliever of stress. The trouble, however, is that far too many of us like to take much more than one drink. Bombarded by stories in the media portraying the medicinal effects of moderate consumption - but with no consistent message on what defines moderation - many drinkers are unclear about the damage they're doing to their health.

Against this background, health authorities struggle to explain that the health benefits of alcohol are largely limited to a few individuals. Indeed, if you look at the issue at the population level, it's clear that we need to 


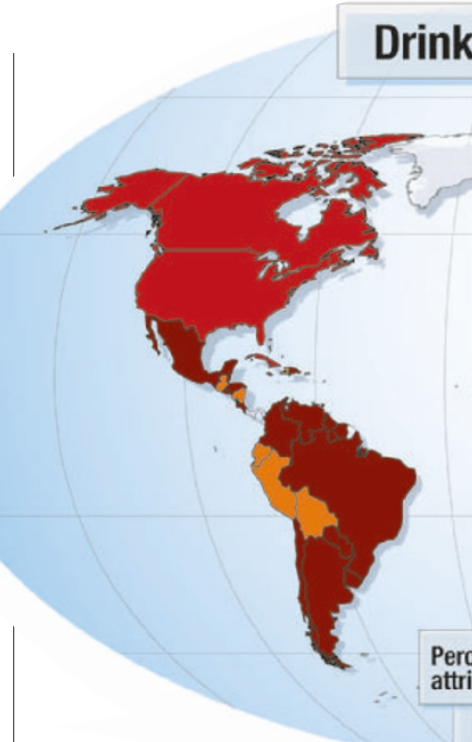

cut back.

"It does present a con-

flict in terms of alcohol policy,"

says Thomas Babor, a health-policy researcher at the University of Connecticut School of Medicine in Farmington.

Epidemiological evidence that alcohol could actually improve health first made an impact in the 1970s. Since then, studies from all over the world have shown that moderate alcohol intake one or two drinks a day - lowers the risk of coronary heart disease by $20-30 \%$ for older men and women ${ }^{2}$.

\section{Little payback}

This basic message is now well known. But the cardiovascular gains from alcohol must be weighed against its numerous evils. Even small amounts of alcohol increase the risk of injury and boost the chances of developing about 60 diseases, including several cancers, liver cirrhosis and neuropsychological disorders. When these are fed into the epidemiological equation, only men over the age of 45 and women over 55 seem to lower their overall health risks by moderate drinking ${ }^{3}$.

Translated into guidelines for sensible drinking, this means that a middle-aged teetotal man, with high cholesterol or a family history of heart disease, would probably benefit by including a single drink a day with dinner. He might, however, achieve the same or better payback by starting to exercise or adopting a healthier diet. And for older people already following an exemplary lifestyle, the benefit reaped from a daily drink is probably marginal.

Those in their 20s and 30s, meanwhile, may start accruing heart benefits from a daily drink, but at this age the threat of accidental injury equals the negligible risk from heart disease, so even moderate drinking seems to offer little payback.

Experts say that an individual's ideal level of consumption should be tailored to

ential sectors of society tend to be drinkers.

"The press lives in a very wet world - and so do the politicians," says Room.

The alcohol industry has also tried hard to disseminate the virtues of its products. In the mid-1990s, the US wine industry proposed bottle labels advertising the health benefits of moderate drinking. Some labels appeared but were quickly abandoned when the US Bureau of Alcohol, Tobacco, Firearms and Explosives provisionally banned such statements in 1999.

Industry representatives argue that they promote responsible drinking by broadcasting or contributing to publichealth campaigns. At the same time, they acknowledge that the medical evidence on alcohol's health benefits has helped them persuade policy-makers of their product's appeal. "It distinguished us from the tobacco companies because we're not seen as inherently bad," says Stephen Whitehead, corporate affairs director with Allied Domecq, a spirits and wine producer based in London.

sound bite" says cardiologist Arthur Klatsky of the healthcare organization Kaiser Permanente in Oakland, California.

Another difficulty in conveying advice on healthy alcohol consumption is the lack of a standard definition for 'a drink'. The alcohol content of any drink varies with its volume and alcohol concentration, so that guidelines advocating a 'moderate' intake are often inconsistent within and between countries. This was highlighted in a December 2003 report ${ }^{4}$ from the International Center for Alcohol Policies in Washington DC. This revealed that a 'standard' drink in Britain contains 8 grams of ethanol, in the United States it contains $14 \mathrm{~g}$ and in Japan $19.75 \mathrm{~g}$.

Even if national health guidelines spell out the limited benefits of moderate drinking, the public tends to hear a

rosier message. Experts pin part of the blame on the media, which, they say, tend to make a splash with studies showing alcohol's benefits, rather than explaining the relative risks. After a 1991 edition of the US TV programme 60 Minutes on the health benefits of wine, trade magazines reported a hike in the next month's wine sales of more than $40 \%$. In part, the soft ride given to alcohol may be linked to the fact that the media and other influ-

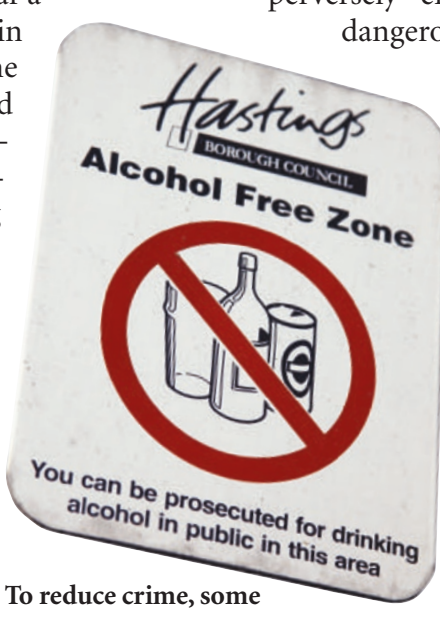

To reduce crime, some towns have banned street drinking.

\section{Global problems}

Given the conflicting messages coming from health authorities, the media and the alcohol industry, it should come as no surprise that drinkers are confused. Clinical psychologist Nancy Piotrowski of Capella University in San Francisco and the Alcohol Research Group in Berkeley, California, has found that more than three-quarters of US healthcare providers did not define moderation in accordance with national guidelines. Her unpublished survey also sampled 130 drinkers in northern California, whose view of moderation was often influenced by their own alcohol consumption. "Many people define 'moderation' as what they do," Piotrowski says.

This means that the message that moderate drinking can promote health may perversely encourage some people into dangerous levels of consumption. "Plenty of people use this message as an excuse to drink more alcohol," argues Ira Goldberg, professor of preventive medicine at Columbia University in New York.

At the population level, the hazards of alcohol are plain to see. Internationally, the highest disease load attributable to alcohol is found in the heavy-drinking former socialist countries of Eastern Europe and in Latin America (see Map, above). Rich developed 
countries have the next biggest problem, with public-health experts being especially worried about binge drinking among the young. Trends differ from country to country - consumption is rising in Britain, for instance, but falling in France and Italy.

In most developing countries, alcohol consumption is still relatively low, but it is climbing steeply, particularly in Asia, driven by economic growth and aggressive marketing. Without intervention, experts predict a future wave of alcohol-related health problems across the developing world.

Governments are mainly trying to tackle the threat posed by alcohol through school education or public-health messages in the media. But given the difficulty of imparting the message of moderation, most experts believe this approach is unlikely to have much effect. "We don't think it'll be successful on its own," says Michael Marmot of University College London. He chaired a working group of Britain's Academy of Medical Sciences that last month ${ }^{5}$ reported on the need to curb heavy drinking in Britain where overall alcohol consumption has risen by $50 \%$ since 1970 .

\section{Strong measures}

What does work, Marmot's working group concluded, after reviewing the evidence from studies conducted worldwide, are more forceful measures to curb consumption. These include raising the minimum legal drinking age, cutting the number of liquor shops, and restricting advertising and the hours during which drink can be sold. Perhaps unsurprisingly, the price of alcohol has a very powerful influence on total consumption (see Graph, right). Most people, it seems, will curtail their drinking if hit hard enough in the pocket.

Experts point to the last few years of the Soviet Union, when excessive drinking was devastating the nation's health. In 1985, Mikhail Gorbachev's government clamped down on the production of illegal alcohol to curtail drunkenness. The move slashed consumption from 14.2 to 10.5 litres of pure alcohol per person per year - and is estimated to have cut the number of alcohol-related deaths from accidents, poisoning and violence by $11 \%$ over five years ${ }^{6}$. But in present-day Russia, alcohol consumption and related mortality have climbed back to pre-1985 levels.

In a one-party state the Soviet leaders didn't have to worry too much about a public backlash. But few democratic politicians are keen to impose higher taxes on alcohol and restrict its sale - there are few votes to be gained, and many potentially to be lost, from such actions.

Marmot's working group acknowledged this difficulty, but pointed to the success of anti-drink-driving campaigns as evidence that initially unpopular moves can be successful. The key to success, the academy's

\section{A little of what you fancy}

Today, the idea that moderate drinking can be beneficial to health is well established. But in the 1980s and 1990s, some sceptics suggested that this effect might be a statistical mirage ${ }^{7}$. Teetotallers, they argued, include ex-alcoholics, the elderly and ill. So the apparent health benefits of moderate drinking could in fact be an artefact.

Some epidemiologists still wonder whether abstainers' relatively poor health is linked to some factor not directly related to their rejection of alcohol. "Non-drinkers are a different type of person," says lan White, who has carried out epidemiological studies of drinking at the UK Medical Research Council's Biostatistics Unit in Cambridge.

But more recent epidemiological analyses have adjusted, so far as is possible, for confounding effects, and still find health benefits from moderate drinking ${ }^{8-10}$. They are backed by studies showing that alcohol benefits the body by boosting levels of 'good' cholesterol and blood proteins that are signs of a healthy heart ${ }^{11}$. "There's not much that can be done to make it more convincing," says epidemiologist Eric Rimm of the Harvard School of Public Health in Boston.

Another issue that has mostly been laid to rest is that wine is better than beer or spirits -

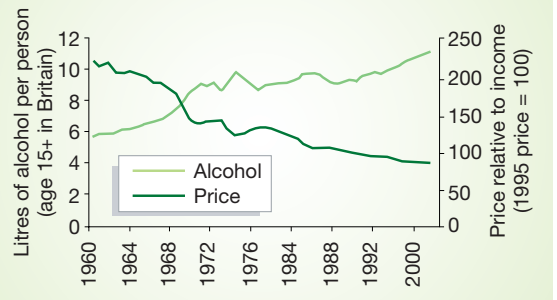

report argued, will be to make the public more aware that measures to restrict the sale of alcohol and increase its price can relieve the unwanted consequences of excessive drinking, including violent crime. "We'd like the public to demand these things," says Marmot.

But in Britain, the academy's message seems to be falling on deaf ears. Just days after the report came out, the UK government released its long-awaited strategy on alcohol. It stressed partnerships between government and the drinks industry to promote sensible drinking, but proposed no increase in the cost of alcohol. At the same time, plans are afoot to extend the time over which British bars are allowed to stay open.

If harder-hitting measures are to be introduced, some experts believe lessons can be learnt from the campaign against tobacco. In that case, the battle was taken to the WHO, which last year adopted the Framework Convention for Tobacco Control. Among other measures, this helps countries to increase

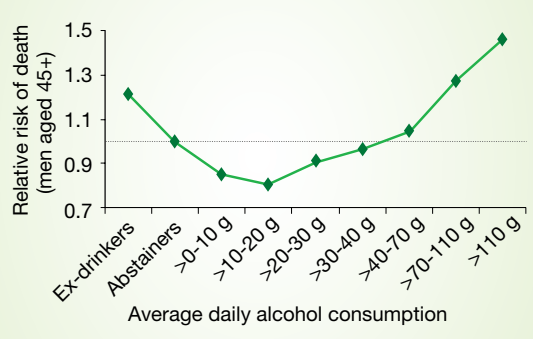

a phenomenon labelled the 'French paradox' because it was thought to explain why citizens of this nation tend to escape heart disease despite an artery-clogging diet. Among many studies contradicting this idea, one of Czech beer drinkers found that those who imbibed four to nine litres each week had the lowest risk of heart disease, compared with those who drank more or less ${ }^{12}$.

The remaining debate is over what constitutes a healthy pattern of drinking. Seven drinks a week can be supped one per day with dinner or downed together in a Friday night. The weight of studies suggests that binge drinking in this way does not protect from heart disease in the same way as spreading it out over several days ${ }^{13}$. "But there's a little uncertainty there," says Rimm.

taxes on tobacco without contravening international trade agreements.

But the convention was only adopted after a long and bruising battle with the tobacco industry, and public-health experts wonder whether the WHO will have the stomach for a similar protracted fight with the drinks industry. Some fear that alcoholrelated health problems will have to reach crisis point before governments and international agencies take concerted action. "Sometimes problems have to escalate before they're convinced to do something drastic," says Babor.

Helen Pearson works in New York for Nature's online news team.

1. Babor, T., Rehm, J. \& Room, R. Alcohol's Role in the Global Burden of Disease: Implications for Alcohol Policy (World Health Organization, Geneva, in the press.)

2. Marmot, M. G. Int. J. Epidemiol. 30, 724-729 (2001).

3. White, I. R., Altmann, D. R. \& Nanchahal, K. Br. Med. J. 325, 191-197 (2002)

4. International Drinking Guidelines (International Center for Alcohol Policies, Washington DC, 2003).

5. Calling Time: The Nation's Drinking as a Major Health Issue (Academy of Medical Sciences, London, 2004).

6. Nemtsov, A.V. Addiction 97, 1413-1425 (2002)

7. Shaper, A. G. Br. J. Addict. 85, 837-847 (1990).

8. Corrao, G., Rubbiati, L., Bagnardi, V., Zambon, A. \& Poikolainen, K. Addiction 95, 1505-1523 (2000).

9. Rehm, J., Gutjahr, E. \& Gmel, G. Contemp. Drug Problems 28, 337-361 (2001)

10. Mukamal, K. J. N. Engl. J. Med. 348, 109-118 (2003)

11. Rimm, E. B., Williams, P., Fosher, K., Criqui, M. \&

Stampfer, M. J. Br. J. Med. 319, 1523-1528 (1999).

12. Bobak, M., Skodova, Z. \& Marmot, M. Br. J. Med. 320, 1378-1379 (2000)

13. Puddey, I. B., Rakic, V., Dimmitt, S. B. \& Beilin, L. J. Addiction 94, 649-663 (1999). 